\title{
Sex differences in body composition and association with cardiometabolic risk
}

\author{
Melanie Schorr' ${ }^{1}$, Laura E. Dichtel', Anu V. Gerweck', Ruben D. Valera' ${ }^{1}$, Martin Torriani ${ }^{2}$, Karen K. Miller ${ }^{1}$ \\ and Miriam A. Bredella $2^{*}$
}

\begin{abstract}
Background: Body composition differs between men and women, with women having proportionally more fat mass and men more muscle mass. Although men and women are both susceptible to obesity, health consequences differ between the sexes. The purpose of our study was to assess sex differences in body composition using anatomic and functional imaging techniques, and its relationship to cardiometabolic risk markers in subjects with overweight/obesity.

Methods: After written informed consent, we prospectively recruited 208 subjects with overweight/obesity who were otherwise healthy (94 men, 114 women, age $37 \pm 10$ years, BMl $35 \pm 6 \mathrm{~kg} / \mathrm{m}^{2}$ ). Subjects underwent dual-energy X-ray absorptiometry (DXA) and computed tomography (CT) for fat and muscle mass, proton MR spectroscopy (1H-MRS) for intrahepatic (IHL) and intramyocellular lipids (IMCL), an oral glucose tolerance test, serum insulin, lipids, and inflammatory markers. Men and women were compared by Wilcoxon signed rank test. Linear correlation and multivariate analyses between body composition and cardiometabolic risk markers were performed.
\end{abstract}

Results: Women and men were of similar mean age and BMI ( $p \geq 0.2)$. Women had higher \%fat mass, extremity fat, and lower lean mass compared to men $(p \leq 0.0005)$. However, men had higher visceral adipose tissue (VAT) and IMCL and higher age-and BMl-adjusted IHL $(p<0.05)$. At similar age and BMI, men had a more detrimental cardiometabolic risk profile compared to women $(p<0.01)$. However, VAT in women, and IMCL in men, were more strongly associated with cardiometabolic risk markers, while more lower extremity fat was associated with a more favorable cardiometabolic profile in women compared to men $(p \leq 0.03)$.

Conclusions: Although the male pattern of fat distribution is associated with a more detrimental cardiometabolic risk profile compared to women of similar age and BMI, VAT is more strongly associated with cardiometabolic risk markers in women, while IMCL are more detrimental in men. Lower extremity fat is relatively protective, in women more than in men. This suggests that detailed anatomic and functional imaging, rather than BMI, provides a more complete understanding of metabolic risk associated with sex differences in fat distribution.

Keywords: Obesity, Body composition, Sex characteristics, Metabolic syndrome, Magnetic resonance spectroscopy, Computed tomography

\section{Background}

Body composition differs between men and women, with women having proportionally more fat mass and men more muscle mass $[1,2]$. Although men and women are both susceptible to obesity, health consequences differ between the sexes [3]. Men have higher cardiovascular mortality, but women have a greater

\footnotetext{
*Correspondence: mbredella@mgh.harvard.edu

${ }^{2}$ Department of Radiology, Massachusetts General Hospital and Harvard

Medical School, Yawkey 6E, 55 Fruit Street, Boston, MA 02114, USA

Full list of author information is available at the end of the article
}

increase in cardiovascular mortality as BMI or waist circumference increases $[4,5]$. This may be in part related to sex-specific differences in fat accumulation as the distribution of fat has a greater impact on cardiometabolic risk than excess total fat mass. For example, ectopic fat depots, such as visceral adipose tissue (VAT), intramyocellular lipids (IMCL), and intrahepatic lipids (IHL), are major risk factors for insulin resistance, dyslipidemia, and the metabolic syndrome, while lower extremity fat may protect against cardiometabolic disease [6-8]. Dual-energy X-ray

(c) The Author(s). 2018 Open Access This article is distributed under the terms of the Creative Commons Attribution 4.0 International License (http://creativecommons.org/licenses/by/4.0/), which permits unrestricted use, distribution, and 
absorptiometry (DXA) can assess total body and appendicular fat and lean mass [9], while computed tomography (CT) and magnetic resonance imaging (MRI) are considered the gold standard for the quantification of different abdominal fat compartments, such as subcutaneous adipose tissue (SAT) and VAT $[10,11]$. Proton magnetic resonance spectroscopy (1H-MRS) is able to determine the amount of IHL $[12,13]$ and IMCL $[14,15]$ non-invasively.

A study from the Framingham Heart cohort has demonstrated positive associations between abdominal adipose tissue compartments and measures of cardiometabolic risk, which were stronger in women compared to men, but the study did not examine associations with ectopic fat depots, such as IHL and IMCL, lower extremity fat or muscle mass [16]. Moreover, a study in subjects at risk for type 2 diabetes mellitus (T2DM) has revealed higher VAT, lower SAT, and higher IMCL in men compared to women; however, the study did not examine the relationship of body composition to markers of cardiometabolic risk [17].

Therefore, the purpose of our study was to assess sex differences in body composition and its relationship to cardiometabolic risk markers in men and women with overweight/obesity. We hypothesized that there are sex differences in body composition and ectopic fat depots and that these are associated with a sex-specific cardiometabolic risk profile.

\section{Methods}

This prospective study was IRB-approved and was HIPAA-compliant. Data were acquired after written informed consent was obtained from all subjects prior to the study.

\section{Subjects}

Our study was performed at a clinical research center. The study group was comprised of 208 subjects (94 men, 114 women) with overweight or obesity who were recruited over 8 years through advertisements for participation in two NIH-funded studies. Inclusion criteria for this analysis were all subjects aged 18 to 65 years. Exclusion criteria were use of anti-hypertensive or cholesterol medications, diabetes mellitus, liver disease or other chronic illnesses, smoking, estrogen or glucocorticoid use, and contraindications to MRI.

Participants underwent DXA, CT, and 1H-MRS for assessment of body composition and ectopic fat depots. An oral glucose tolerance test was performed in all subjects and fasting and 2-h glucose was assessed. Insulin was measured in 63 men and 73 women. The homeostasis model assessment of insulin resistance
(HOMA-IR), a marker of insulin resistance, was assessed. Serum lipids [triglycerides, total, high density lipoprotein (HDL), and low-density lipoprotein (LDL) cholesterol] were measured in all subjects. Apolipoprotein B (ApoB) was measured in 59 men and 77 women, and ApoB/LDL, a marker of atherogenicity, was calculated. Inflammatory markers [high-sensitivity C-reactive protein (hsCRP) and fibrinogen] were measured in 59 men and 77 women. Metabolic syndrome was defined as by the National Cholesterol Education Program criteria (NCEP Adult Treatment Panel III) [18].

Main outcome measures (IHL and IMCL) have been previously reported in a subset of study subjects $(62$ men and 79 women) [12, 15, 19-23]; however, none of the clinical characteristics, measures of cardiometabolic risk, and body composition have been reported in the entire cohort and no sex differences in body composition have been assessed.

\section{Dual-energy x-ray absorptiometry (DXA)}

Subjects underwent DXA (Discovery A; Hologic Inc.) for assessment of total fat mass, percent body fat (\%fat), lower extremity fat mass, and appendicular lean mass. The relative amount of lower extremity fat was calculated as the ratio of lower extremity fat mass over total fat mass. The relative amount of appendicular lean mass was calculated as the ratio of appendicular lean mass over total body weight. Coefficients of variation $(\mathrm{CV})$ of DXA in our laboratory are $1.7 \%$ for fat and $2.4 \%$ for lean soft tissue mass.

\section{Computed tomography (CT)}

Subjects underwent single slice CT (LightSpeed Pro, GE Healthcare) of the abdomen through the mid-portion of the L4 level and the left mid-thigh. Measurements performed at the L4 level have been shown to correlate with abdominal adipose tissue volumes in men and women and with cardiometabolic risk [24, 25]. Scan parameters were standardized: 144 table height, $80 \mathrm{kV}$ (abdomen), $120 \mathrm{kV}$ (thigh), $70 \mathrm{~mA}$ (abdomen), $170 \mathrm{~mA}$ (thigh), gantry rotation time $2 \mathrm{~s}, 1 \mathrm{~cm}$ slice thickness, and 48 field of view.

Abdominal and thigh adipose tissues were identified using a threshold set for -50 to -250 Hounsfield units (HU) [26], and abdominal and thigh SAT, VAT, and thigh muscle cross-sectional areas (CSA) $\left(\mathrm{cm}^{2}\right)$ were separated by manual delineation. VAT/SAT was calculated to assess the relative amount of VAT. Analyses were performed using Osirix software version 3.2.1 (www.osirix-viewer.com/index.html). CV of CT in our laboratory are $2.5 \%$ for fat and $1.1 \%$ for muscle CSA. 


\section{Proton MR spectroscopy (1H-MRS)}

Subjects underwent $1 \mathrm{H}$-MRS of the liver to determine IHL and of the soleus muscle to determine IMCL after an overnight fast using a 3.0-T MRI system (Siemens Trio, Siemens Medical Systems). All subjects were asked to avoid moderate or vigorous exercise or high-fat diet $72 \mathrm{~h}$ prior to scanning. CV for measurements at our institution are $8 \%$ for IHL and $6 \%$ for IMCL quantification.

\section{H-MR spectroscopy of liver}

For $1 \mathrm{H}$-MRS of the liver, a voxel measuring $20 \times 20 \times$ $20 \mathrm{~mm}(8 \mathrm{~mL})$ was placed within the right hepatic lobe, avoiding vessels or artifacts. For each voxel placement, automated optimization of gradient shimming was performed. Single breath-hold single-voxel 1H-MRS data were acquired using a point-resolved spatially localized spectroscopy (PRESS) pulse sequence without water suppression with the following parameters: TR of $1500 \mathrm{~ms}$, TE of $30 \mathrm{~ms}, 8$ acquisitions, 1024 data points, and receiver bandwidth of $2000 \mathrm{~Hz}$.

\section{H-MR spectroscopy of soleus muscle}

For $1 \mathrm{H}$-MRS of soleus muscle, the right calf was placed in a transmit/receive quadrature extremity coil (USA Instruments, Aurora, Ohio). A voxel measuring $15 \times 15 \times 15 \mathrm{~mm}(3.4 \mathrm{~mL})$ was placed in the soleus muscle, avoiding interstitial fat or vessels. Single-voxel $1 \mathrm{H}$-MRS data was acquired using a PRESS pulse sequence with a TR of $3000 \mathrm{~ms}$, TE of $30 \mathrm{~ms}, 64$ acquisitions, 1024 data points, and receiver bandwidth of $1000 \mathrm{~Hz}$. Frequency selective water signal suppression was used for metabolite acquisition, and unsuppressed water spectra of the same voxel were obtained for each scan with the same parameters as the metabolite acquisition except for the use of eight acquisitions. For each voxel placement, automated optimization of gradient shimming, water suppression, and transmit-receive gain were performed, followed by manual adjustment of gradient shimming targeting water linewidths of $<20 \mathrm{~Hz}$.

\section{H-MR spectroscopy data analysis}

Fitting of all 1H-MRS data was performed using LCModel (version 6.3-0K). Fitting algorithms specific for liver lipid estimates $(0.9,1.3$, and $2.0 \mathrm{ppm})$ were scaled to unsuppressed water peak $(4.7 \mathrm{ppm})$ and expressed as lipid-to-water ratio. For soleus muscle, IMCL (1.3 ppm) and EMCL (1.5 ppm) methylene estimates were automatically scaled to unsuppressed water peak (4.7 ppm) and expressed as lipid-to-water ratio.

\section{Statistical analysis}

JMP Statistical Database Software (version 12; SAS Institute) was used for statistical analyses. Men and women were compared using the Wilcoxon signed rank test. The Bonferroni method was used to control for multiple comparisons. Multivariate standard least squares regression modeling was performed to control for age and BMI on log-transformed data. Linear correlation analyses between body composition and measures of cardiometabolic risk were performed and nonparametric Spearman's rank correlation coefficients are reported. Data are shown as median and interquartile range. Statistical significance was defined as a two-tailed $p<0.05$, and $p \leq 0.1$ was used to denote a trend.

\section{Results}

Clinical characteristics and sex differences in body composition as assessed by CT, DXA, and 1H-MRS are shown in Tables 1 and 2. Women and men were of similar age and BMI. As expected, men were on average heavier and taller compared to women resulting in similar BMI.

Sex differences in body composition as assessed by dualenergy $x$-ray absorptiometry (DXA)

There was no significant difference in mean total fat mass by DXA between men and women. However, women had higher mean \%fat mass and higher mean lower extremity fat and higher lower extremity fat/ total fat mass compared to men, while men had higher mean appendicular lean mass and appendicular lean mass/weight. These differences were independent of age and BMI (Table 1).

\section{Sex differences in body composition as assessed by computed tomography (CT)}

Men had higher mean VAT and VAT/SAT compared to women while women had higher thigh SAT and men higher thigh muscle CSA, independent of age and BMI. There was a trend toward higher mean abdominal SAT in women, which became significant after controlling for age and BMI. (Figs. 1 and 2, and Table 1).

\section{Sex differences in body composition as assessed by proton MR spectroscopy (1H-MRS)}

There was a trend of higher mean IHL in men, which became significant after controlling for age and BMI. Men also had higher mean soleus IMCL compared to women, independent of age and BMI (Figs. 1 and 2, Table 1).

\section{Sex differences in cardiometabolic risk markers}

Cardiometabolic risk markers of men and women are shown in Table 2. At similar mean age and BMI, men had a more detrimental cardiometabolic risk profile with impaired measures of glucose homeostasis (higher mean fasting insulin and HOMA-IR), serum lipids 
Table 1 Clinical characteristics and body composition (median, IQR)

\begin{tabular}{|c|c|c|c|}
\hline Variable & Men $(n=94)$ & Women $(n=114)$ & $p$ \\
\hline \multicolumn{4}{|l|}{ Clinical characteristics } \\
\hline Age (years) & $34.5,28.8-42.0$ & $38.0,29.8-43.3$ & 0.2 \\
\hline Height (cm) & $177,173-183$ & $163,158-168$ & $<0.0001$ \\
\hline Weight (kg) & $105,96-124$ & 91, 78-101 & $<0.0001$ \\
\hline Body mass index $\left(\mathrm{kg} / \mathrm{m}^{2}\right)$ & $34,31-39$ & $34,29-38$ & 0.4 \\
\hline \multicolumn{4}{|l|}{ DXA parameters } \\
\hline Total fat mass (kg) & $34,29-48$ & $38,31-47$ & $0.4^{\#}$ \\
\hline Total fat mass (\%) & $33.4,28.5-37.5$ & $42.2,38.3-45.9$ & $<0.0001^{* \#}$ \\
\hline Lower extremity fat (kg) & $12,10-16$ & $14,11-18$ & $0.001^{* \#}$ \\
\hline Lower extremity fat/total fat & $0.38,0.35-0.42$ & $0.33,0.30-0.36$ & $<0.0001^{* \#}$ \\
\hline Appendicular lean mass (kg) & $33,29-37$ & $23,20-25$ & $<0.0001^{* \#}$ \\
\hline Appendicular lean mass/weight & $0.30,0.28-0.33$ & $0.25,0.23-0.27$ & $<0.0001^{* \#}$ \\
\hline \multicolumn{4}{|l|}{ CT parameters } \\
\hline Abdominal SAT $\left(\mathrm{cm}^{2}\right)$ & $386,292-560$ & $455,325-567$ & $0.07^{* \#}$ \\
\hline Visceral adipose tissue (VAT) $\left(\mathrm{cm}^{2}\right)$ & $149,122-208$ & 106, 69-139 & $<0.0001^{* \#}$ \\
\hline VAT/SAT & $0.36,0.25-0.54$ & $0.23,0.17-0.33$ & $<0.0001^{* \#}$ \\
\hline Thigh SAT $\left(\mathrm{cm}^{2}\right)$ & $128,94-148$ & $171,136-233$ & $<0.0001^{* \#}$ \\
\hline Thigh muscle $\left(\mathrm{cm}^{2}\right)$ & $198,177-219$ & $141,124-153$ & $<0.0001^{* \#}$ \\
\hline \multicolumn{4}{|l|}{${ }^{1} \mathrm{H}$-MRS parameters } \\
\hline Intrahepatic lipids (lipid/water) & $0.06,0.03-0.17$ & $0.05,0.02-0.13$ & $0.1^{* \#}$ \\
\hline Soleus intramyocellular lipids (lipid/water) & $0.04,0.02-0.05$ & $0.03,0.02-0.04$ & $0.0005^{* \#}$ \\
\hline
\end{tabular}

Abbreviations: DXA dual energy x-ray absorptiometry, $C T$ computed tomography, SAT subcutaneous adipose tissue, $1 \mathrm{H}-\mathrm{MRS}$ proton magnetic resonance spectroscopy

*Significant after controlling for age

"Significant after controlling for BMI

(lower mean HDL cholesterol, higher triglycerides, higher $\mathrm{ApoB}$, and $\mathrm{ApoB} / \mathrm{LDL}$ ), and higher fibrinogen than women. Despite similar mean age and BMI, there was a higher prevalence of the metabolic syndrome in men compared to women (Table 2).

\section{Sex-specific associations of body composition and measures of cardiometabolic risk}

Separate analyses of men and women revealed sex-specific differences in the associations between measures of body composition and cardiometabolic risk, which were independent of age and BMI.

VAT was associated with measures of impaired glucose homeostasis (fasting glucose, 2-h glucose, fasting insulin, HOMA-IR), serum lipids (total, HDL, and LDL cholesterol, triglycerides, ApoB), and inflammatory markers (hsCRP, fibrinogen) in men and women; however, many associations were stronger in women or not significant in men (Table 3).

IHL was associated with cardiometabolic risk markers in men and women; however, there were sex-specific differences. The associations between IHL and fasting glucose, apolipoprotein B, and fibrinogen were significant in women but not in men, while the associations between IHL and HDL cholesterol and hsCRP were significant in men but not in women (Table 4).

IMCL were positively associated with inflammatory markers (fibrinogen, hsCRP) in men but not in women (Table 4).

Lower extremity fat mass/total fat mass was associated with favorable measures of glucose homeostasis (2-h glucose, fasting insulin, HOMA-IR) and serum lipids (triglycerides, ApoB, ApoB/LDL) in men and women, independent of age and BMI; however, many associations were stronger in women or not significant in men (Table 5).

Appendicular lean mass/weight was associated with favorable measures of glucose homeostasis (fasting insulin, HOMA-IR) in men, improved lipid profile in women (total cholesterol, LDL cholesterol, triglycerides, ApoB), and lower inflammatory markers (hsCRP, fibrinogen) in both sexes (Table 5). 
Table 2 Cardiometabolic risk parameters (median, IQR)

\begin{tabular}{|c|c|c|c|}
\hline Variable & Men $(n=94)$ & Women $(n=114)$ & $p$ \\
\hline \multicolumn{4}{|l|}{ Glucose parameters } \\
\hline Fasting glucose (mg/dL) & $85,80-90$ & $86,81-92$ & 0.4 \\
\hline OGTT 2-h glucose (mg/dL) & $114,95-133$ & $119,98-134$ & 0.6 \\
\hline Fasting insulin (uU/mL) & $14,9-18$ & $8,5-10$ & $<0.0001^{\dagger * \#}$ \\
\hline HOMA-IR & $2.6,1.7-3.7$ & $1.5,1.0-2.2$ & $<0.0001^{\dagger * \#}$ \\
\hline \multicolumn{4}{|l|}{ Lipid parameters } \\
\hline Total cholesterol (mg/dL) & $172,151-194$ & $177,156-202$ & 0.2 \\
\hline HDL cholesterol (mg/dL) & $38,33-43$ & $51,43-59$ & $<0.0001^{\dagger * \#}$ \\
\hline LDL cholesterol (mg/dL) & $107,93-125$ & $106,87-128$ & 0.7 \\
\hline Triglyceride level (mg/dL) & $111,82-160$ & $89,69-127$ & $0.001^{\dagger * \#}$ \\
\hline Apolipoprotein B (ApoB) (mg/dL) & $95,84-110$ & $85,69-106$ & $0.01^{* \#}$ \\
\hline ApoB/LDL & $0.88,0.83-0.98$ & $0.79,0.70-0.87$ & $<0.0001^{\dagger * \#}$ \\
\hline \multicolumn{4}{|l|}{ Inflammatory parameters } \\
\hline hsCRP (ng/L) & $2.4,1.4-6.0$ & $2.9,1.3-5.5$ & 0.8 \\
\hline Fibrinogen (mg/dL) & $395,344-452$ & $475,419-523$ & $<0.0001^{\dagger * \#}$ \\
\hline Metabolic syndrome $(n, \%)$ & $34(37 \%)$ & $19(17 \%)$ & $0.002^{+}$ \\
\hline
\end{tabular}

Abbreviations: HOMA-IR homeostatic model assessment of insulin resistance, OGTT oral glucose tolerance test, $H D L$ high-density lipoprotein, $L D L$ low-density lipoprotein, $h s C R P$ high-sensitivity C-reactive protein

${ }^{+}$Significant after controlling for multiple comparisons

*Significant after controlling for age

"Significant after controlling for BMI

\section{Discussion}

Our study demonstrated differences in body composition between men and women with overweight/obesity. While women had a higher percent total fat mass and men more lean and muscle mass, detailed assessment of ectopic fat compartments revealed higher VAT, IHL, and IMCL in men while women had more lower extremity fat. At similar age and BMI, this male anthropometric phenotype was associated with a more detrimental cardiometabolic risk profile compared to the female phenotype. However, VAT was more strongly associated with measures of adverse cardiometabolic risk in women compared to men, while IMCL were more detrimental in men. Interestingly, relatively higher lower extremity fat mass was associated with a more favorable cardiometabolic risk profile and this was stronger in women than in men. Relatively higher appendicular lean mass was protective against cardiometabolic risk, and this was seen in both sexes.

There has been great interest in physiologic differences between men and women and the risk of cardiometabolic disease. The incidence and health outcomes in cardiometabolic disease differ between the sexes with men having a higher prevalence of cardiometabolic disease. However, although mortality is higher in men than women across the weight spectrum, the sex-specific increase in mortality is greater in women than men as BMI increases $[4,5]$. This may be at least in part related to sex-specific differences in body composition. While women have relatively more fat mass and men more lean mass, less is known about sex differences in ectopic fat depots and their impact on cardiometabolic risk. Advances in imaging technology allow the comprehensive assessment of different fat compartments, including ectopic lipids, lean, and muscle mass [9-15]. A unique aspect of our study is the assessment of body composition by a combination of anatomic and functional imaging techniques. We used DXA to determine total body and appendicular fat and lean mass. However, DXA is not able to accurately quantify VAT and SAT. We therefore used CT to assess VAT, SAT, and thigh muscle. $1 \mathrm{H}$-MRS has been shown to be an accurate technique to measure IHL and IMCL non-invasively [12-15], and we were able to quantify IHL and IMCL in our subjects with overweight/obesity.

Our study showed higher VAT, a strong risk factor for impaired glucose homeostasis, dyslipidemia, and the metabolic syndrome [7, 27], in men compared to women despite similar age and BMI. This is consistent with the propensity of men to accumulate fat in the abdomen (apple-shaped body type) while women had more lower extremity fat mass (pear-shaped body type). However, when we analyzed women and men 

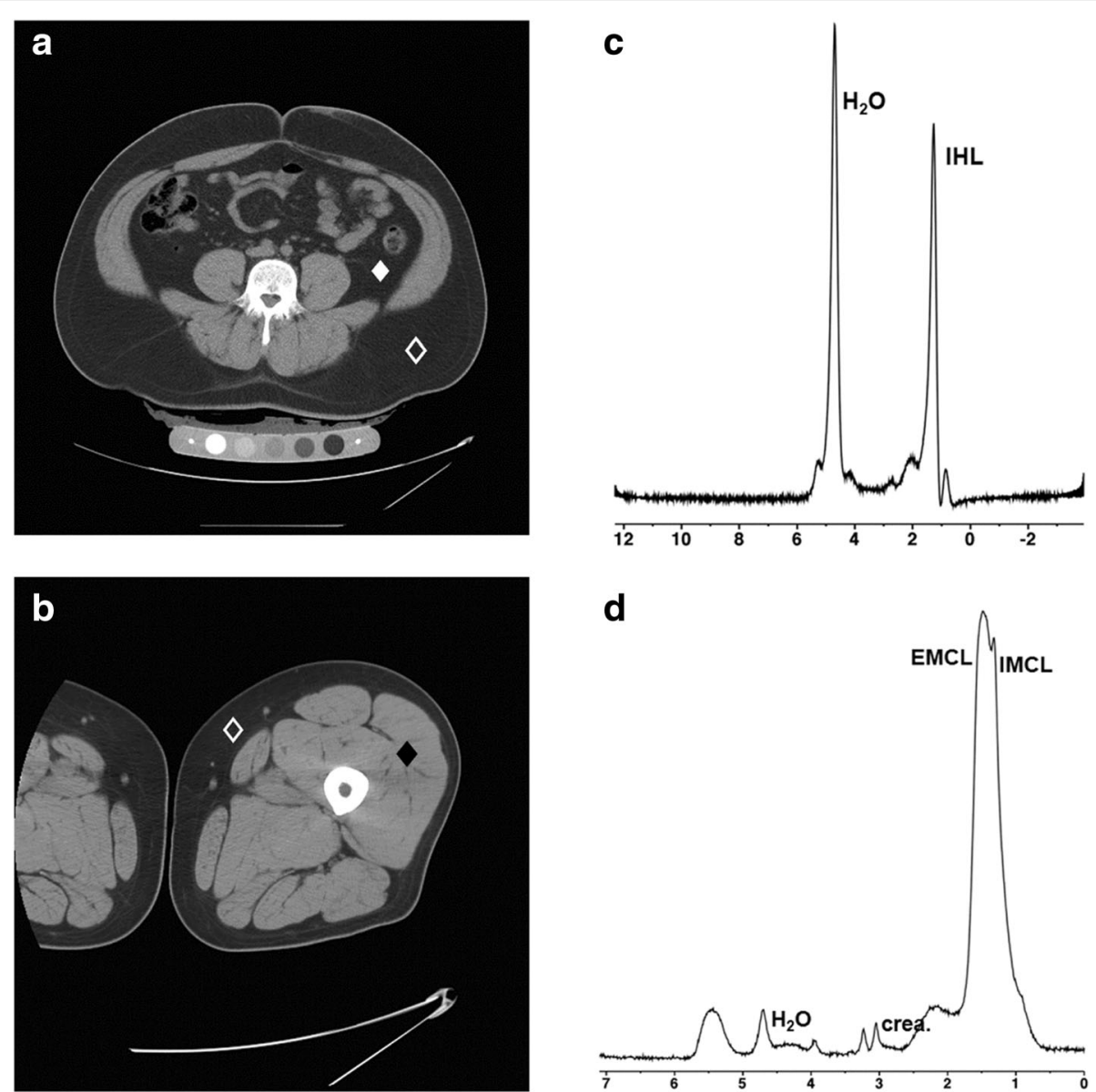

Fig. $1 \mathrm{CT}$ and 1H-MRS for body composition in a 35-year-old man with obesity (BMl $37 \mathrm{~kg} / \mathrm{m}^{2}$ ). Fasting LDL cholesterol $118 \mathrm{mg} / \mathrm{dL}, \mathrm{HDL}$ cholesterol $39 \mathrm{mg} / \mathrm{dL}$, triglycerides $74 \mathrm{mg} / \mathrm{dL}$, glucose $84 \mathrm{mg} / \mathrm{dL}$, insulin $19 \mu \mathrm{U} / \mathrm{mL}$, HOMA-IR 3.3, 2-h glucose from oral glucose tolerance test $144 \mathrm{mg} / \mathrm{dL}$. a CT of the abdomen at the level of $L 4$ for quantification of visceral adipose tissue $\left(194 \mathrm{~cm}^{2}\right)$ (white diamond) and subcutaneous adipose tissue (open diamond) $\left(458 \mathrm{~cm}^{2}\right)$. $\mathbf{b}$ CT of the mid-thigh for quantification of subcutaneous adipose tissue (open diamond) $\left(123 \mathrm{~cm}^{2}\right)$ and muscle (black diamond) $\left(207 \mathrm{~cm}^{2}\right)$. c $1 \mathrm{H}-\mathrm{MR}$ spectrum of the right hepatic lobe for intrahepatic lipid quantification showing lipid $(1.3 \mathrm{ppm})$ and unsuppressed water $(4.7 \mathrm{ppm})$ resonances. Lipid to water ratio was 0.8 . d $1 \mathrm{H}-\mathrm{MR}$ spectrum of soleus muscle for intramyocellular lipid quantification showing intramyocellular lipid methylene protons $(-\mathrm{CH} 2)$ at $1.3 \mathrm{ppm}(\mathrm{IMCL})$, extramyocellular lipid methylene protons $(-\mathrm{CH} 2)$ at $1.5 \mathrm{ppm}(\mathrm{EMCL})$, residual water peak at $4.7 \mathrm{ppm}$, and creatine $(-\mathrm{CH} 2)$ resonance at $3.0 \mathrm{ppm}$. IMCL/unsuppressed water ratio was 0.06

separately, VAT was more strongly associated with markers of cardiometabolic risk in women compared to men. This is consistent with a study from the Framingham Heart cohort, in which VAT was more strongly associated with cardiometabolic risk factors in women compared to men [16]. This suggests that although women have less VAT than men overall, VAT accumulation in women confers greater cardiometabolic risk compared to men.

An important complication of obesity is elevated IHL content, which can lead to nonalcoholic fatty liver disease (NAFLD) and nonalcoholic steatohepatitis (NASH), which may progress to liver fibrosis and cirrhosis [6]. In our study, men had higher age-and BMI-adjusted IHL, assessed by a simple breath hold
$1 \mathrm{H}$-MRS sequence, compared to women of similar age and BMI. Men also had higher IMCL, which may play an etiologic role in the pathogenesis of insulin resistance. A recent study in lean men who underwent overfeeding for 8 weeks suggested that the size and location of lipid droplets, rather than the total IMCL content, are determinants of the increase in insulin resistance in this setting [28]. However, high IMCL content as determined by $1 \mathrm{H}-\mathrm{MRS}$ has been shown in states of insulin resistance, type 2 diabetes mellitus (T2DM), and dyslipidemia [29]. Our finding of higher IMCL in men is consistent with a study by Machann et al. who assessed sex differences in body composition in 150 healthy volunteers across a wide age range who were at risk for developing T2DM [17]. 

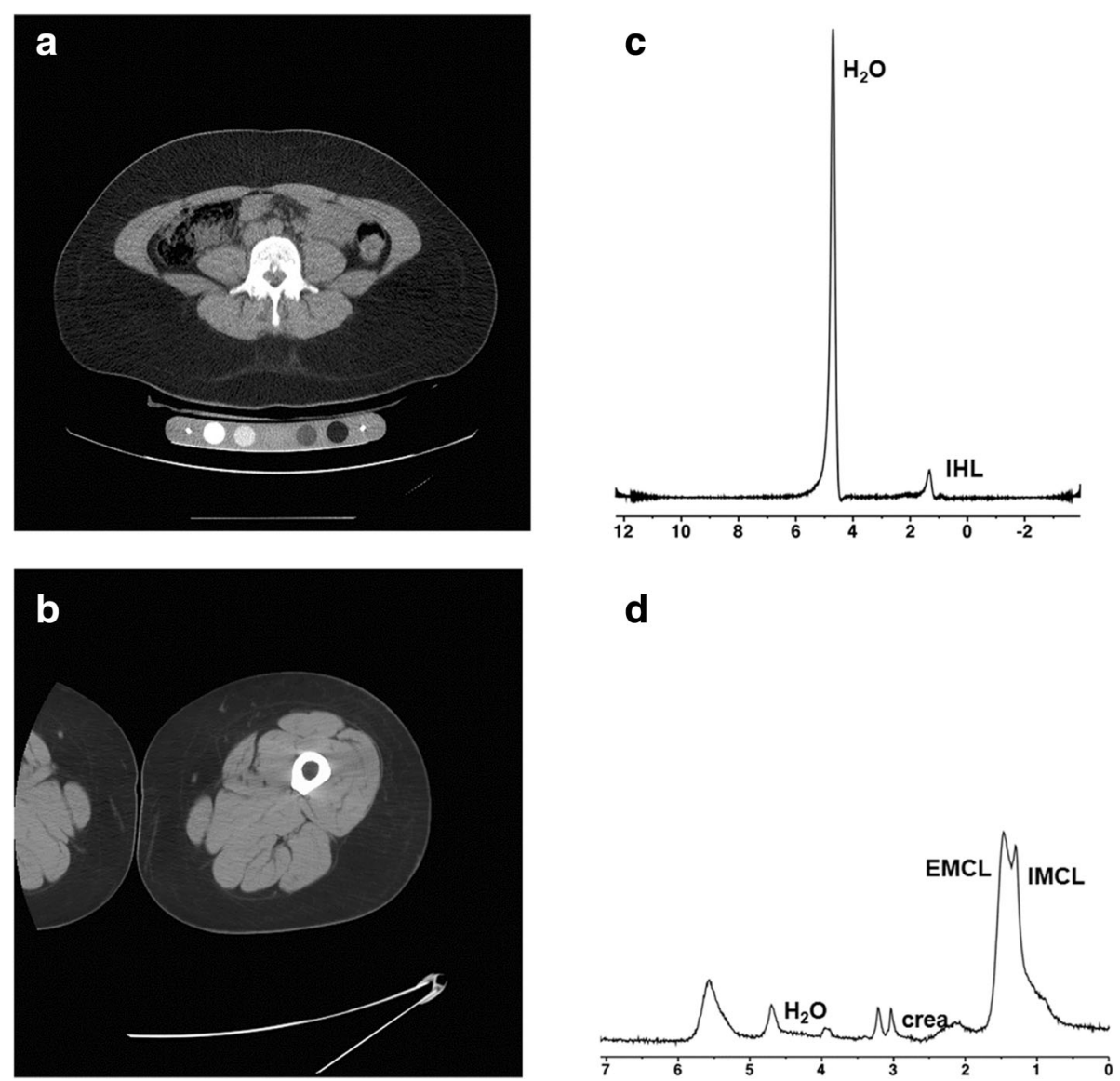

Fig. $2 \mathrm{CT}$ and $1 \mathrm{H}$-MRS for body composition in a 35-year-old woman with obesity (BMI $38 \mathrm{~kg} / \mathrm{m}^{2}$ ). Despite similar age and BMl, the woman had lower visceral adipose tissue and thigh muscle cross sectional area (CSA), lower intrahepatic and intramyocellular lipids and higher thigh subcutaneous adipose tissue compared to the man in Fig. 1, and this was associated with a more favorable cardiometabolic risk profile compared to the man. Fasting LDL cholesterol $104 \mathrm{mg} / \mathrm{dL}$, HDL cholesterol $59 \mathrm{mg} / \mathrm{dL}$, triglycerides $50 \mathrm{mg} / \mathrm{dL}$, glucose $72 \mathrm{mg} / \mathrm{dL}$, insulin $3 \mu \mathrm{U} / \mathrm{mL}$, HOMA-IR 0.48 , 2-h glucose from oral glucose tolerance test $84 \mathrm{mg} / \mathrm{dL}$. a CT of the abdomen at the level of L4 for quantification of visceral adipose tissue $\left(30 \mathrm{~cm}^{2}\right)$ and subcutaneous adipose tissue $\left(450 \mathrm{~cm}^{2}\right)$. b CT of the mid-thigh for quantification of subcutaneous adipose tissue $\left(208 \mathrm{~cm}^{2}\right)$ and muscle $\left(110 \mathrm{~cm}^{2}\right)$. c $1 \mathrm{H}-\mathrm{MR}$ spectrum of the right hepatic lobe for intrahepatic lipid quantification showing lipid (1.3 ppm) and unsuppressed water $(4.7 \mathrm{ppm}$ ) resonances. Lipid to water ratio was 0.01. For purposes of visual comparison, the amplitude of unsuppressed water in Figs. 1c and $2 \mathrm{c}$ were scaled identically. $\mathbf{d} 1 \mathrm{H}-\mathrm{MR}$ spectrum of soleus muscle for intramyocellular lipid quantification showing intramyocellular lipid methylene protons $(-\mathrm{CH} 2)$ at $1.3 \mathrm{ppm}(\mathrm{IMCL})$, extramyocellular lipid methylene protons $(-\mathrm{CH} 2)$ at $1.5 \mathrm{ppm}(\mathrm{EMCL})$, residual water peak at $4.7 \mathrm{ppm}$, and creatine $(-\mathrm{CH} 2)$ resonance at $3.0 \mathrm{ppm}$. IMCL/unsuppressed water ratio was 0.02 . For purposes of visual comparison, the amplitude of total creatine peaks in Figs. $1 \mathrm{~d}$ and $2 \mathrm{~d}$ were scaled identically

Interestingly, IMCL were associated with higher inflammatory markers in men but not in women. We also found sex-specific differences in associations between IHL and cardiometabolic risk markers. While IHL was positively associated with fasting glucose, apolipoprotein $\mathrm{B}$, and fibrinogen in women but not in men, IHL was associated with lower HDL cholesterol and higher hsCRP in men but not in women. This suggests that accumulation of IHL has different effects on glucose and lipid metabolism between the sexes.

Preferential accumulation of fat in the lower body (femorogluteal fat) has been shown to be relatively protective against cardiometabolic risk [7, 8, 30]. Consistent with this, we found more lower extremity fat in women than in men. Our observed more favorable cardiometabolic risk profile in women compared to men, despite similar age and BMI, might be in part due to greater lower extremity fat mass in women. Although lower extremity fat mass has been shown to be protective against cardiometabolic disease, sex differences between lower extremity fat and cardiometabolic risk are unknown. In our study, relative higher lower extremity fat mass was associated with more favorable measures of cardiometabolic risk and these associations were stronger in women than in men.

In our study, men had a worse cardiometabolic risk profile with impaired measures of glucose homeostasis, 
Table 3 Relationship between visceral adipose tissue and cardiometabolic risk markers

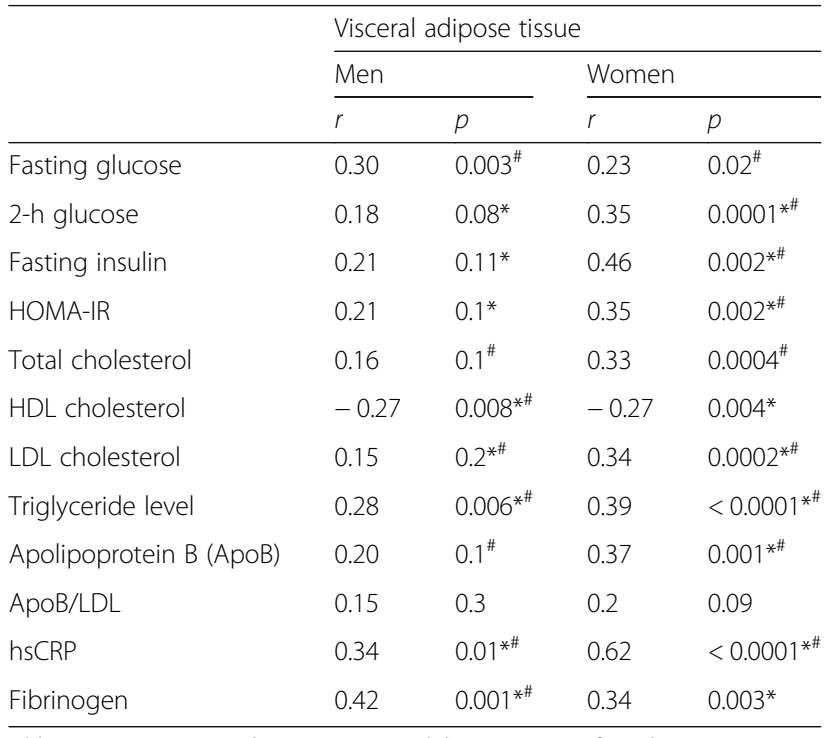

Abbreviations: HOMA-IR homeostatic model assessment of insulin resistance, $H D L$ high-density lipoprotein, $L D L$ low-density lipoprotein, $h s C R P$ highsensitivity C-reactive protein

*Significant after controlling for age

${ }^{\text {\#Significant after controlling for BMI }}$

dyslipidemia and increased inflammatory markers and higher prevalence of the metabolic syndrome than women despite similar age and BMI. This is consistent with a study in premenopausal women and men of similar age, in which women were found to have more total body fat but lower VAT than men, which was associated with a more favorable cardiometabolic risk profile [31].
Skeletal muscle plays an important role in the regulation of glucose homeostasis [32], and low muscle mass contributes to increased risk of T2DM $[33,34]$. Although men are known to have more muscle mass than women [1], less is known about sex differences in muscle mass and cardiometabolic risk. We found sex differences in appendicular lean mass normalized over weight which was associated with improved measures of glucose homeostasis in men, a more favorable lipid profile in women, and lower inflammatory markers in both sexes. These findings suggest that increasing muscle mass may be able to offset some of the detrimental effects of ectopic fat in men and women with obesity independent of changes in fat mass.

Potential mechanism for sex differences in body composition and its relationship with cardiometabolic risk include modulation by sex steroids. For example, low estrogen levels, as in menopause, are associated with preferential accumulation of VAT and increased cardiometabolic risk [35, 36], and low testosterone in men can lead to visceral adiposity [37]. Moreover, results of recent genome wide association studies (GWAS) have identified sex-specific genetic determinants of fat accumulation [38].

A limitation of our study is the cross-sectional study design. Longitudinal data are necessary to assess whether sex-specific differences in ectopic fat depots will translate into higher incidence of cardiometabolic disease. Furthermore, our observed sex differences and the differences in cardiometabolic risk do not imply

Table 4 Relationship between ectopic fat depots and cardiometabolic risk markers

\begin{tabular}{|c|c|c|c|c|c|c|c|c|}
\hline & \multicolumn{4}{|c|}{ Intrahepatic lipids } & \multicolumn{4}{|c|}{ Soleus intramyocellular lipids } \\
\hline & \multicolumn{2}{|l|}{ Men } & \multicolumn{2}{|c|}{ Women } & \multicolumn{2}{|l|}{ Men } & \multicolumn{2}{|c|}{ Women } \\
\hline & $r$ & $p$ & $\bar{r}$ & $p$ & $r$ & $p$ & $r$ & $p$ \\
\hline Fasting glucose & 0.15 & 0.3 & 0.32 & $0.01^{* \#}$ & 0.12 & 0.3 & 0.007 & 1.0 \\
\hline 2-h glucose & 0.30 & $0.02^{*}$ & 0.40 & $0.001^{* \#}$ & 0.08 & 0.5 & -0.09 & 0.5 \\
\hline Fasting insulin & 0.62 & $<0.0001^{* \#}$ & 0.61 & $<0.0001^{* \#}$ & 0.15 & 0.3 & -0.01 & 1.0 \\
\hline HOMA-IR & 0.59 & $0.0003^{* \#}$ & 0.60 & $<0.0001^{* \#}$ & 0.16 & 0.2 & -0.02 & 0.9 \\
\hline Total cholesterol & 0.09 & 0.5 & 0.20 & 0.1 & 0.10 & 0.4 & -0.09 & 0.5 \\
\hline HDL cholesterol & -0.44 & $0.0003^{* \#}$ & -0.19 & $0.1^{*}$ & -0.02 & 0.9 & 0.11 & 0.4 \\
\hline LDL cholesterol & 0.10 & 0.5 & 0.14 & 0.3 & 0.06 & 0.6 & -0.15 & 0.3 \\
\hline Triglyceride level & 0.39 & $0.002^{* \#}$ & 0.57 & $<0.0001^{* \#}$ & 0.13 & 0.3 & -0.03 & 0.8 \\
\hline Apolipoprotein B (ApoB) & 0.18 & 0.3 & 0.34 & $0.03^{* \#}$ & 0.12 & 0.4 & -0.21 & 0.2 \\
\hline ApoB/LDL & 0.47 & $0.006^{\#}$ & 0.42 & $0.007^{* \#}$ & 0.12 & 0.4 & -0.03 & 0.8 \\
\hline hsCRP & 0.47 & $0.01^{* \#}$ & 0.37 & 0.09 & 0.31 & $0.05^{*}$ & 0.41 & 0.06 \\
\hline Fibrinogen & 0.21 & 0.2 & 0.50 & $0.001^{* \#}$ & 0.44 & $0.002^{*}$ & 0.15 & 0.4 \\
\hline
\end{tabular}

Abbreviations: HOMA-IR homeostatic model assessment of insulin resistance, $H D L$ high-density lipoprotein, $L D L$ low-density lipoprotein, $h s C R P$ high-sensitivity

$\mathrm{C}$-reactive protein

*Significant after controlling for age

\#Significant after controlling for BMI 
Table 5 Relationship between body composition and cardiometabolic risk markers

\begin{tabular}{|c|c|c|c|c|c|c|c|c|}
\hline & \multicolumn{4}{|c|}{ Lower extremity fat/total fat } & \multicolumn{4}{|c|}{ Appendicular lean mass/weight } \\
\hline & \multicolumn{2}{|l|}{ Men } & \multicolumn{2}{|c|}{ Women } & \multicolumn{2}{|l|}{ Men } & \multicolumn{2}{|c|}{ Women } \\
\hline & $r$ & $p$ & $r$ & $\mathrm{p}$ & $r$ & $\mathrm{p}$ & $r$ & $p$ \\
\hline Fasting glucose & 0.0002 & 1.0 & -0.17 & $0.08^{* \#}$ & -0.20 & $0.06^{* \#}$ & -0.20 & 0.03 \\
\hline 2-h glucose & -0.16 & $0.2^{*}$ & -0.36 & $0.0002^{* \#}$ & -0.08 & 0.5 & -0.14 & 0.1 \\
\hline Fasting insulin & -0.26 & $0.05^{* \#}$ & -0.40 & $0.0005^{* \#}$ & -0.48 & $<0.0001^{* \#}$ & -0.16 & 0.2 \\
\hline HOMA-IR & -0.24 & $0.06^{* \#}$ & -0.40 & $0.0004^{* \#}$ & -0.49 & $<0.0001^{* \#}$ & -0.17 & 0.2 \\
\hline Total cholesterol & -0.09 & 0.4 & -0.13 & 0.2 & 0.03 & 0.8 & -0.21 & $0.02^{\#}$ \\
\hline HDL cholesterol & 0.22 & $0.05^{*}$ & 0.10 & 0.3 & 0.13 & 0.2 & 0.08 & $0.4^{*}$ \\
\hline LDL cholesterol & -0.10 & 0.4 & -0.09 & 0.4 & 0.07 & 0.5 & -0.19 & $0.04^{\#}$ \\
\hline Triglyceride level & -0.20 & 0.08 & -0.25 & $0.01^{* \#}$ & -0.14 & 0.2 & -0.24 & 0.009 \\
\hline Apolipoprotein B (ApoB) & -0.10 & 0.5 & -0.25 & $0.03^{* \#}$ & 0.09 & 0.5 & -0.21 & $0.06^{\#}$ \\
\hline ApoB/LDL & -0.20 & 0.1 & -0.27 & $0.02^{*}$ & -0.13 & 0.3 & -0.14 & 0.2 \\
\hline hsCRP & -0.08 & 0.6 & -0.17 & 0.3 & -0.40 & $0.003^{*}$ & -0.35 & 0.02 \\
\hline Fibrinogen & -0.29 & $0.02^{*}$ & -0.09 & 0.4 & -0.41 & $0.001^{*}$ & -0.37 & $0.0008^{*}$ \\
\hline
\end{tabular}

Abbreviations: HOMA-IR homeostatic model assessment of insulin resistance, $H D L$ high-density lipoprotein, $L D L$ low-density lipoprotein, $h s C R P$ high-sensitivity C-reactive protein

* Significant after controlling for age

"Significant after controlling for BMI

causality and may be multifactorial, including lifestyle (diet, exercise) and genetic variations.

\section{Conclusion}

Body composition differs between men and women and the male pattern of fat distribution is associated with higher cardiometabolic risk markers compared to women of similar age and BMI; however, VAT in women, and IMCL in men, is more detrimental to cardiometabolic health, while lower extremity fat is relatively more protective in women than in men. IHL were detrimental to both sexes with sex-specific differences in associations between IHL and cardiometabolic risk markers. This suggests that detailed anatomic and functional imaging, rather than BMI, provides a more complete understanding of metabolic risk associated with sex differences in fat distribution.

\section{Funding}

This work was supported through the following NIH grants: R01 DK-095792, R01 HL-077674, K23 RR-23090, K24 DK-109940, K24 HL092902, UL1 RR025758, P30DK040561, and M01 RR01066.

\section{Availability of data and materials}

The datasets generated and/or analyzed during the current study are not publicly available due to ongoing studies but are available from the corresponding author on reasonable request.

\section{Authors' contributions}

MAB, KKM, MS, LED, AVG, RDV, and MT made substantial contributions to conception and design, or acquisition of data, or analysis and interpretation of data. MS, LED, AVG, RDV, KKM, and MAB were involved in patient recruitment and performance of all clinical components of the study. MT and $M A B$ were responsible for all imaging components of the study. MS, $L E D, A V G, R D V, M T, K K M$, and MAB were involved in drafting the manuscript or revising it critically for important intellectual content. MS, LED, AVG, RDV, MT, KKM, and MAB have given final approval of the version to be published.
Ethics approval and consent to participate

The study was approved by Partners IRB (protocol 2012 P002276 and 2012P002410), and written informed consent was obtained from all subjects.

\section{Consent for publication}

$\mathrm{N} / \mathrm{A}$

Competing interests

The authors declare that they have no competing interests.

\section{Publisher's Note}

Springer Nature remains neutral with regard to jurisdictional claims in published maps and institutional affiliations.

\section{Author details}

${ }^{1}$ Neuroendocrine Unit, Massachusetts General Hospital and Harvard Medical School, Bulfinch 457B, 55 Fruit Street, Boston, MA 02114, USA. ²Department of Radiology, Massachusetts General Hospital and Harvard Medical School, Yawkey 6E, 55 Fruit Street, Boston, MA 02114, USA.

Received: 30 May 2018 Accepted: 13 June 2018

Published online: 27 June 2018

\section{References}

1. Abe T, Kearns CF, Fukunaga T. Sex differences in whole body skeletal muscle mass measured by magnetic resonance imaging and its distribution in young Japanese adults. Br J Sports Med. 2003:37:436-40.

2. Karastergiou K, Smith SR, Greenberg AS, Fried SK. Sex differences in human adipose tissues - the biology of pear shape. Biol Sex Differ. 2012;3:13.

3. Power ML, Schulkin J. Sex differences in fat storage, fat metabolism, and the health risks from obesity: possible evolutionary origins. Br J Nutr. 2008:99:931-40.

4. Arnold AM, Psaty BM, Kuller LH, et al. Incidence of cardiovascular disease in older Americans: the cardiovascular health study. J Am Geriatr Soc. 2005:53:211-8.

5. Song $X$, Tabak AG, Zethelius $B$, et al. Obesity attenuates gender differences in cardiovascular mortality. Cardiovasc Diabetol. 2014;13:144.

6. Angulo P. Nonalcoholic fatty liver disease. N Engl J Med. 2002:346:1221-31.

7. Bjorntorp P. Regional patterns of fat distribution. Ann Intern Med. 1985;103: 994-5.

8. Snijder MB, Visser M, Dekker JM, et al. Low subcutaneous thigh fat is a risk factor for unfavourable glucose and lipid levels, independently of high abdominal fat. The health ABC study. Diabetologia. 2005;48:301-8. 
9. Bredella MA, Ghomi RH, Thomas BJ, et al. Comparison of DXA and CT in the assessment of body composition in premenopausal women with obesity and anorexia nervosa. Obesity (Silver Spring). 2010;18:2227-33.

10. Abate N, Burns D, Peshock RM, et al. Estimation of adipose tissue mass by magnetic resonance imaging: validation against dissection in human cadavers. J Lipid Res. 1994:35:1490-6.

11. Rossner $\mathrm{S}, \mathrm{Bo}$ WJ, Hiltbrandt $\mathrm{E}$, et al. Adipose tissue determinations in cadavers-a comparison between cross-sectional planimetry and computed tomography. Int J Obes. 1990;14:893-902.

12. Bredella MA, Ghomi RH, Thomas BJ, et al. Breath-hold $1 \mathrm{H}$-magnetic resonance spectroscopy for intrahepatic lipid quantification at 3 tesla. J Comput Assist Tomogr. 2010;34:372-6.

13. Szczepaniak LS, Babcock EE, Schick F, et al. Measurement of intracellular triglyceride stores by $\mathrm{H}$ spectroscopy: validation in vivo. Am J Phys. 1999; 276:E977-89.

14. Boesch C, Slotboom J, Hoppeler H, Kreis R. In vivo determination of intramyocellular lipids in human muscle by means of localized $1 \mathrm{H}-\mathrm{MR}-$ spectroscopy. Magn Reson Med. 1997;37:484-93.

15. Bredella MA, Ghomi RH, Thomas BJ, et al. Comparison of 3.0 T proton magnetic resonance spectroscopy short and long echo-time measures of intramyocellular lipids in obese and normal-weight women. J Magn Reson Imaging. 2010;32:388-93.

16. Fox CS, Massaro JM, Hoffmann U, et al. Abdominal visceral and subcutaneous adipose tissue compartments: association with metabolic risk factors in the Framingham heart study. Circulation. 2007;116:39-48.

17. Machann J, Thamer C, Schnoedt B, et al. Age and gender related effects on adipose tissue compartments of subjects with increased risk for type 2 diabetes: a whole body MRI / MRS study. MAGMA. 2005;18:128-37.

18. Executive Summary of. The third report of the National Cholesterol Education Program (NCEP) expert panel on detection, evaluation, and treatment of high blood cholesterol in adults (adult treatment panel III). JAMA. 2001:285:2486-97.

19. Bredella MA, Gerweck AV, Lin E, et al. Effects of $G H$ on body composition and cardiovascular risk markers in young men with abdominal obesity. J Clin Endocrinol Metab. 2013;98:3864-72.

20. Bredella MA, Gill CM, Gerweck AV, et al. Ectopic and serum lipid levels are positively associated with bone marrow fat in obesity. Radiology. 2013;269:534-41.

21. Bredella MA, Lin E, Brick DJ, et al. Effects of $\mathrm{GH}$ in women with abdominal adiposity: a 6-month randomized, double-blind, placebo-controlled trial. Eur J Endocrinol. 2012;166:601-11.

22. Bredella MA, Torriani M, Ghomi RH, et al. Adiponectin is inversely associated with intramyocellular and intrahepatic lipids in obese premenopausal women. Obesity (Silver Spring). 2010;19:911-6.

23. Bredella MA, Torriani M, Thomas BJ, et al. Peak growth hormone-releasing hormone-arginine-stimulated growth hormone is inversely associated with intramyocellular and intrahepatic lipid content in premenopausal women with obesity. J Clin Endocrinol Metab. 2009;94:3995-4002.

24. Ryo M, Kishida K, Nakamura T, et al. Clinical significance of visceral adiposity assessed by computed tomography: a Japanese perspective. World J Radiol. 2014;6:409-16.

25. Yang L, Samarasinghe YP, Kane $P$, et al. Visceral adiposity is closely correlated with neck circumference and represents a significant indicator of insulin resistance in WHO grade III obesity. Clin Endocrinol. 2010;73:197-200.

26. Borkan GA, Gerzof SG, Robbins AH, et al. Assessment of abdominal fat content by computed tomography. Am J Clin Nutr. 1982;36:172-7.

27. Tchernof A, Despres JP. Pathophysiology of human visceral obesity: an update. Physiol Rev. 2013;93:359-404.

28. Covington JD, Johannsen DL, Coen PM, et al. Intramyocellular lipid droplet size rather than total lipid content is related to insulin sensitivity after 8 weeks of overfeeding. Obesity (Silver Spring). 2017;25:2079-87.

29. Shulman Gl. Cellular mechanisms of insulin resistance. J Clin Invest. 2000; 106:171-6.

30. Manolopoulos KN, Karpe F, Frayn KN. Gluteofemoral body fat as a determinant of metabolic health. Int J Obes. 2010;34:949-59.

31. Lemieux S, Despres JP, Moorjani S, et al. Are gender differences in cardiovascular disease risk factors explained by the level of visceral adipose tissue? Diabetologia. 1994;37:757-64.

32. DeFronzo RA, Tripathy D. Skeletal muscle insulin resistance is the primary defect in type 2 diabetes. Diabetes Care. 2009;32(Suppl 2):S157-63.
33. Larsen BA, Wassel CL, Kritchevsky SB, et al. Association of muscle mass, area, and strength with incident diabetes in older adults: the health $A B C$ study. J Clin Endocrinol Metab. 2016;101:1847-55.

34. Park SW, Goodpaster BH, Lee JS, et al. Excessive loss of skeletal muscle mass in older adults with type 2 diabetes. Diabetes Care. 2009;32:1993-7.

35. Ley CJ, Lees B, Stevenson JC. Sex- and menopause-associated changes in body-fat distribution. Am J Clin Nutr. 1992;55:950-4.

36. Lovejoy JC, Champagne CM, de Jonge $L$, et al. Increased visceral fat and decreased energy expenditure during the menopausal transition. Int J Obes. 2008;32:949-58.

37. Allan CA, Strauss BJ, Burger HG, et al. Testosterone therapy prevents gain in visceral adipose tissue and loss of skeletal muscle in nonobese aging men. J Clin Endocrinol Metab. 2008:93:139-46.

38. Randall JC, Winkler TW, Kutalik Z, et al. Sex-stratified genome-wide association studies including 270,000 individuals show sexual dimorphism in genetic loci for anthropometric traits. PLoS Genet. 2013;9:e1003500.

\section{Ready to submit your research? Choose BMC and benefit from:}

- fast, convenient online submission

- thorough peer review by experienced researchers in your field

- rapid publication on acceptance

- support for research data, including large and complex data types

- gold Open Access which fosters wider collaboration and increased citations

- maximum visibility for your research: over $100 \mathrm{M}$ website views per year

At BMC, research is always in progress.

Learn more biomedcentral.com/submissions 